\title{
Guest Editorial: Responsible Research in Marketing
}

\author{
Michael Haenlein ${ }^{1,2} \cdot$ Mary Jo Bitner $^{3} \cdot$ Ajay K. Kohli ${ }^{4} \cdot$ Katherine N. Lemon ${ }^{5} \cdot$ David J. Reibstein $^{6}$
}

Accepted: 20 August 2021 / Published online: 4 September 2021

(c) Academy of Marketing Science 2021

\section{Introduction}

We thank the editors of the Journal of the Academy of Marketing Science for the opportunity to share our thoughts about responsible research in marketing. This editorial aims to recap the general objectives and core principles of the responsible research movement as embodied in RRBM (Responsible Research in Business \& Management, https:// www.rrbm.network/) and to bring them to life for researchers in marketing. The concept of responsible research goes back to the work of Anne Tsui and stipulates that business research should serve society by being useful as well as credible (i.e., reliable and valid). RRBM was created as a virtual, global organization combining leading scholars, major accreditation bodies, and leading schools worldwide. RRBM's overarching Vision 2030 and its action orientation promote a future where business schools worldwide

Michael Haenlein

haenlein@escp.eu

Mary Jo Bitner

maryjo.bitner@asu.edu

Ajay K. Kohli

kohli@gatech.edu

Katherine N. Lemon

kay.lemon@bc.edu

David J. Reibstein

reibstein@wharton.upenn.edu

ESCP Business School, Paris, France

2 University of Liverpool Management School at the University of Liverpool, Liverpool, UK

3 W. P. Carey School of Business at Arizona State University, Tempe, AZ, USA

4 Scheller College of Business at Georgia Tech, Atlanta, GA, USA

5 Carroll School of Management at Boston College, Chestnut Hill, MA, USA

6 Wharton School at the University of Pennsylvania, Philadelphia, PA, USA are known for producing societally relevant, credible, and useful research. In its position paper (RRBM 2017), RRBM outlines seven principles related to those dimensions: service to society (RRBM Principle 1), credibility (RRBM Principles 2, 3, 4), and usefulness (RRBM Principles 5, 6, 7). Responsible research is gaining increasing prominence in marketing. We hope that this editorial can serve as a call for action in three ways: by providing a framework for thinking about responsible research in marketing, giving examples of prior work, and highlighting some areas for future research. The following section will explain the seven RRBM principles before conceptualizing the dimension of usefulness in a marketing context.

\section{Responsible research in marketing}

\section{Service to society}

Marketing, like many other fields, is at a critical juncture. Academic research in marketing is published in outlets primarily read by academics to the near exclusion of other stakeholders. Promotion and tenure decisions tend to be based on the number of academic publications and citations garnered rather than the impact of the publications on marketing stakeholders and the betterment of society. In parallel, businesses are increasingly focusing on stakeholder (vs. mere shareholder) value. Having a societal purpose has become increasingly important for attracting and retaining employees and customers. Business school students are increasingly interested in having businesses better serve society. Several scholars have voiced concerns that much academic research fails to address issues of importance to marketers, consumers, policymakers, and the broader society (Kohli \& Haenlein, 2021; Van Heerde et al., 2021). To remain relevant, business research in general and research in marketing, in particular, must devote more attention to developing new knowledge that benefits businesses and the broader society for the ultimate purpose of creating a better world (RRBM Principle 1). 
Responsible research in marketing - that benefits various stakeholders and the broader society-calls for individual research projects to have two characteristics. First, responsible research must be credible, that is, provide findings, tools, propositions, or frameworks that can be trusted. Second, responsible research must be useful, that is, have the potential to change the behavior of one or more major stakeholders in ways that improve their wellbeing or that of the broader society or the planet. In recognition of the importance of responsible research, major academic business journals across disciplines have recently highlighted research that serves society. Examples in marketing include the special issue on "Better Marketing for a Better World" in the Journal of Marketing (2021) and the forthcoming special issue on "Reimagining Marketing Strategy" in the Journal of the Academy of Marketing Science (2022). We briefly discuss these two criteria - credibility and usefulness-and then elaborate on the latter in a subsequent section.

\section{Credibility}

Research credibility refers to the extent to which marketing stakeholders can trust the claims (or conclusions) of a piece of research. Credibility results from the rigor with which a research project is executed. Importantly, research credibility rests equally on theoretical rigor and methodological rigor, even though the latter typically receives more attention. Theoretical rigor does not necessarily refer to borrowing theories or frameworks from established disciplines like psychology or economics and applying them to marketing problems. Instead, it refers to the precision with which a study's constructs are defined and the soundness of the logic that is advanced for claimed cause-effect relationships, independent of whether they are organic to marketing or borrowed from other disciplines (see Kohli \& Haenlein, 2021).

Like theoretical rigor, methodological rigor is important for assuring research credibility (RRBM Principle 4). At the same time, an obsession with methodological rigor can undermine the second criterion of responsible research — usefulness-by discouraging new research on issues of importance to stakeholders. We, therefore, suggest that research credibility be viewed as the confidence that the claims or findings of a piece of research are "not wrong," rather than whether the most advanced statistical or econometric techniques have been used (Kohli \& Haenlein, 2021; Lehmann et al., 2011). This calls for distinguishing between research whose aim is to propose the presence of effects versus that whose aim is to estimate the size of (known or presumed) effects as accurately as possible. The latter type of research can benefit from advances in methodological techniques more so than the former. For this reason, we suggest judging research credibility based on "relevant rigor" rather than the heuristic of whether the most advanced technical machinery has been used. Importantly, both basic and applied contributions, as well as research using a variety of methodologies, can fulfill such a goal (RRBM Principle 2).

\section{Usefulness}

In addition to being credible, responsible research needs to be useful. Usefulness is not merely the quality of being relevant because even unimportant issues can be relevant (in the sense of being related to marketing). Instead, usefulness implies that the research has the potential to change the behaviors of one or more stakeholders to have a positive impact on business, the broader society, or the planet (RRBM Principle 6). The list of potential stakeholders includes the ones traditionally considered in marketing (e.g., managers, customers, academics, policymakers) but can also include accreditation bodies, funding agencies, business school deans, and public news media (e.g., Table 1 in Bolton, 2020). Ideally, these stakeholders should be actively involved (e.g., through incentives, co-creation of research agendas, recognition of useful research, or publicizing such research) without compromising the independence or autonomy of the research (RRBM Principle 5).

The breadth of major stakeholders likely to be positively impacted and the magnitude of the impact are key indicators of the usefulness of the research. Responsible research need not directly lead to a positive impact on major stakeholders, society, or the planet. Instead, it may lead to or enable other research that, in turn, leads to those positive outcomes. In these instances, research may be judged to be useful provided there is a "line of sight" from the research to subsequent research and eventual positive impact on major stakeholders, society, or the planet.

Given the breadth of possible marketing stakeholder groups to be considered, the eventual usefulness of research requires broad dissemination of research findings to ensure awareness among relevant stakeholder groups (RRBM Principle 7). Therefore, the usefulness of research may be enhanced via the publication of key findings in the popular press, business outlets targeted at managers, and focused outlets targeted at other stakeholders. It is noteworthy that accreditation bodies such as AACSB and journal ranking media such as the Financial Times are beginning to consider usefulness or societal impact as important criteria in assessing research value.

\section{Dimensions of usefulness for responsible research in marketing}

Building on these RRBM principles, we propose that research usefulness in marketing may be viewed as comprising two dimensions-impact magnitude and impact breadth-as shown in Fig. 1. Impact magnitude refers to the 
extent of potential change in the behavior of one or more marketing stakeholders leading to an improvement in the wellbeing of a stakeholder, society, or planet. Impact breadth refers to the span of entities that are likely to be impacted by a piece of research (i.e., a firm, its immediate stakeholders, broader society, and planet).

\section{Usefulness to the firm and immediate stakeholders}

As shown in Fig. 1 left panel, the focus of marketing scholars historically has been on the firm (shareholders) and a subset of immediate stakeholders (primarily consumers, and secondarily customers, managers, and employees). To be useful, research should lead to a significant change in the behavior of one or more of these groups and/or improve their wellbeing. However, much of our research focused on these traditional stakeholders leads to minimal or very small changes in their behaviors or wellbeing (marked as "prominent current emphasis" in Fig. 1). The magnitude of impact, as shown on the Y-axis in Fig. 1, is small. To be more useful, research should lead to greater behavioral change and/or greater wellbeing of more of these stakeholders.

To be sure, not all prior research has been unimpactful. It is instructive to look at prior research that has built new theory and impacted how executives manage marketing activities, resources, and organizations. For instance, research on understanding, measuring, and managing a firm's service quality has helped build new theory and influenced industry practice in a big way. Similarly, research on measuring and managing brand equity has had a significant impact, as has the research on market-based assets and shareholder value. Other examples include work on customer equity, customer lifetime value, marketing strategy, and cultural change.
Research on consumer wellbeing is relatively nascent, but a good example includes research focused on consumer financial decision making, which has enabled consumers to have more secure retirements, reduce debt more quickly, and, in general, make better financial decisions. The broader transformative consumer research movement focused on making a difference in the lives of consumers is another good example.

Moreover, useful research can impact the behavior and wellbeing of multiple stakeholders. For example, recent research has begun to examine how addressing potential biases in technological algorithms and models (e.g., artificial intelligence, social media, news feeds, video streaming) can result in better outcomes for firms as well as consumers. Research on the wellbeing of a firm's employees is relatively sparse, but there are welcome signs of interest in this topic. For example, recent research examines the impact of salesforce compensation schemes on salespeople's health and wellbeing. These are encouraging signs; more such research focusing on multiple stakeholders is needed.

\section{Usefulness for society and planet}

As noted above, much of what marketing academics have focused on historically are dependent variables such as improved sales, market share, profits, customer equity, and ultimately shareholder value. Research on other topics (e.g., customer satisfaction, consumer choice) has also typically been linked directly to these financial outcomes for firms. The expanding circles on the right-hand side of Fig. 1 illustrate a broadening of contexts, outcomes, and dependent variables for academic marketing research. The widening circles suggest that we should expand our focus
Fig. 1 Usefulness of responsible research in marketing
Dimensions of Usefulness

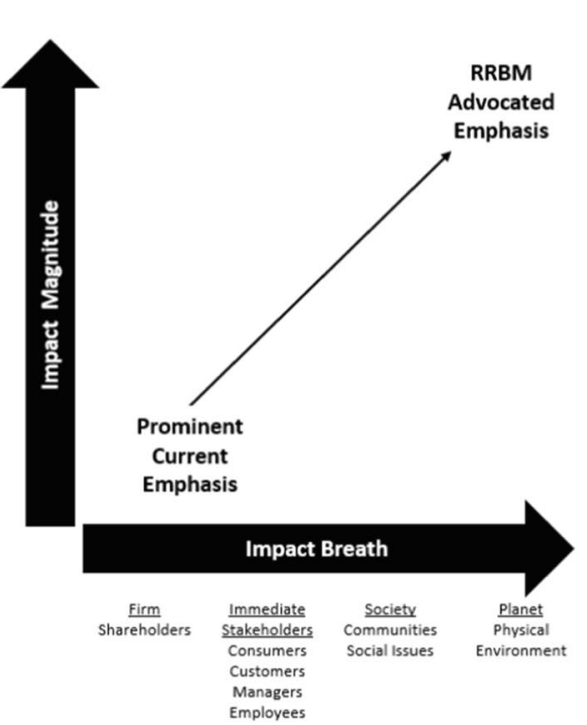

Expanded Dependent Variables

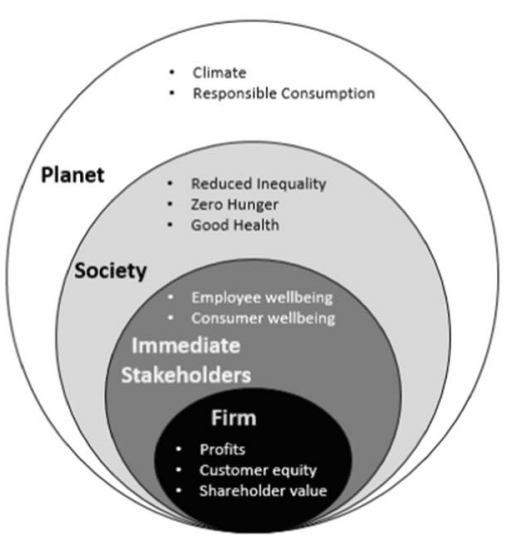


to include additional dependent variables. While there is some work on the latter coming out of the transformative consumer and service research domains, there is room for much more. As we extend outward even further, we see many other non-firm-related outcomes that could be considered in our research. This could include outcomes such as reduced education and income inequality, reduced hunger or homelessness, better public health, and even planet-level sustainability goals such as climate change action and reductions in carbon footprint.

These broader objectives could be achieved through societally beneficial corporate behavior, such as green products, employee wellness programs, sustainable supply chain practices, or responsible consumption. Alternatively, they could be achieved by directly addressing the issues facing society independent of firms' actions. Many of these types of societal objectives are captured in the United Nation's 17 Sustainable Development Goals (SDGs) and the agenda and platforms of the World Economic Forum. While there is some work by marketing scholars emerging on these broad, societal topics, and there are journals publishing articles and a few special issues in these areas, there is not enough.

\section{Illustrative areas for useful future research}

As discussed earlier, research is more useful when it has a greater positive impact on a stakeholder (impact magnitude) and/or impacts a broader set of stakeholders (impact breadth). We offer examples of issues that may be examined in future research to potentially impact one or more of the four stakeholders-firms, immediate stakeholders, society, planet-in significant ways. We first discuss some illustrative issues of significance for firms and immediate stakeholders, and then society and planet.

\section{Research focusing on the firm and immediate stakeholders}

A major set of marketing issues facing firms today revolve around digital technologies such as mobile phones, augmented reality, video or mobile games, and edge computing. While some of these domains have been addressed, many remain. For example, what organizational challenges do firms face when incorporating digital technologies into marketing activities? What are some novel ways of addressing these challenges? How can firms use digital technologies to increase their customer-centricity, grow revenues and build market shares? Which of these are more effective, and why?

Similarly, future research could examine a number of issues focused on a firm's immediate stakeholders. For example, how do firms' reward and recognition policies affect the health of their employees? How does consumers' purchasing behavior affect societal needs? What can firms do to protect consumer privacy while still being able to reach target customers effectively? What techniques can firms use to reduce potential biases against certain customer groups? How can firms take consumer contexts (e.g., negative events from climate change such as floods, wildfires, or extreme weather) into account when designing and managing customer experience? What can firms do to improve financial decision-making by consumers? Answers to questions like these hold the promise of significantly impacting one or more stakeholders and/or changing their behaviors.

\section{Research focusing on society and planet}

Many forces, including accrediting bodies, rankings groups, and society at large, encourage business school academics to undertake research with greater societal and even planetary impact. Many faculty, especially younger academics and $\mathrm{Ph} . \mathrm{D}$. students, are eager to embrace research that would have a broader, societal impact. However, many scholars are wondering what exactly that might mean in terms of research areas and topics. As suggested earlier, a way to start is to think in terms of different societal dependent variables such as reducing poverty, hunger, pollution, or illiteracy, for example, or increasing wellbeing or resiliency. Alternatively, consider research that has a broader societal or planetary impact. For specific examples of this type of research, see the AMA-EBSCO-RRBM awards for 2019 and 2020.

In many cases, such research might merely mean taking traditional research methods and theories and focusing on a societal context (e.g., non-profits, emerging markets, underserved communities) where current knowledge could be applied and extended for broader benefit. For example, how can established marketing communication theories and practices be applied and extended to solve the vexing challenges of vaccinating the world during the Covid pandemic crisis? Much of the behavioral research on charitable giving would be a good example of socially oriented research. What new product and service innovations might be discovered to address hunger and/or homelessness challenges in local communities or at a larger scale? How does our knowledge of service quality and service design extend or require adaptation in the context of education, health, or societal wealth disparity? What metrics should we be using to assess societal impact? More broadly still, marketing academics can bring their knowledge and theories to bear on planetary topics. To do this successfully would likely require developing expertise in a particular planetary domain (e.g., climate, energy, sustainable ocean life) to understand the issues and where knowledge of marketing strategy, products, services, and consumers might contribute to solving the challenges. To address these issues, marketing academics might find that they need to become part of interdisciplinary teams (RRBM 
Principle 3) across business domains or even work with nonbusiness disciplines such as engineering or medicine.

\section{Conclusion}

We have discussed several aspects of credible and useful research, which represent the core of responsible research. We hope our discussion helps clarify how the concepts of societal impact, credibility, and usefulness apply in a marketing context. It is important for researchers in all areas of marketing to conduct more research that significantly changes the behavior of consumers, managers, policymakers, and/or organizations in ways that positively impact their wellbeing, that of the broader society and/or planet. This includes being conscious of potential negative impacts of marketing actions at all levels. We are encouraged to see more marketing scholars paying greater attention to the usefulness of their current and proposed research projects. It is important that we accelerate the developing momentum. That is in our enlightened self-interest and in the interest of accelerating better business practices, ultimately creating a better world.

\section{References}

Bolton, R. N. (2020). First steps to creating high impact theory in marketing. AMS Review, 10(3-4), 172-178.

Heerde, V., Harald, J., Christine Moorman, C., Moreau, P., \& Palmatier, R. W. (2021). Reality Check: Infusing Ecological Value into Academic Marketing Research. Journal of Marketing, 85(2), $1-13$.

Kohli, A. K., \& Haenlein, M. (2021). Factors affecting the study of important marketing issues: Implications and recommendations. International Journal of Research in Marketing, 38(1), 1-11.

Lehmann, D. R., McAlister, L., \& Staelin, R. (2011). Sophistication in Research in Marketing. Journal of Marketing, 75(4), 155-165.

RRBM Co-founders of (2017) A vision for responsible research in business and management: Striving for useful and credible knowledge, Position Paper, accessible from www.rrbm.network

Publisher's note Springer Nature remains neutral with regard to jurisdictional claims in published maps and institutional affiliations. 